DOI: 10.20472/IAC.2019.051.008

\title{
GERGELY FARKAS
}

University of Szeged, Faculty of Economics and Business Administration, Hungary

\section{ÉVA MÁLOVICS}

University of Szeged, Faculty of Economics and Business Administration, Hungary

\section{BEÁTA KINCSESNÉ VAJDA}

University of Szeged, Faculty of Economics and Business Administration, Hungary

\section{BASIC VALUES AND ENTREPRENEURIAL BEHAVIOUR IN FAMILY AND NON-FAMILY SMALL AND MEDIUM-SIZED FIRMS}

\begin{abstract}
:
We used the Schwartz theory of basic values to examine the effect of them on entrepreneurial behaviour. According to the literature, family businesses tend to act in business based on family values. In non-family business, the connection between the leader's values and the organizational values is less tight. We measured entrepreneurial behaviour with Entrepreneurial Orientation (EO), Learning Orientation (LO), Growth Orientation (GO), and three more dimensions about how the entrepreneurs connect to their business environment. The study used survey method and reached 298 small and medium-sized firms in the Southern Great Plain region of Hungary.

Results show that family and non-family entrepreneurs only differ in conservation values (security, conformity, tradition). This is a well-known difference in the literature. However, our primary goal was to compare groups of family and non-family entrepreneurs when a quadrant of the basic value model has a higher or lower value than the median of the sample. This way, we found, those family businesses with a high value of openness to change (stimulation, self-direction) have higher EO and GO. Both groups with a high value of self-transcendence have higher LO. Family firms with high conservation values have higher LO; meanwhile, in non-family businesses, the higher openness to change is associated with higher LO. We expected higher self-enchantment (achievement, power, hedonism) might lead to higher EO, but it stands only for family firms.

The pattern of connection of basic values and behaviour differs in the case of family and non-family firms. Our study confirms that the effect of leader's basic values is less visible on entrepreneurial behaviour in case of non-family firms, but it exists. In case of family firms, the higher conservation values benefit as higher EO and LO and more intense networking in behaviour.
\end{abstract}

\section{Keywords:}

Entrepreneurial Orientation, Learning Orientation, Growth Orientation, family business

JEL Classification: L26, 030, D23 